\title{
Biologically Active Phytocomplex for Correction of Carbohydrate Metabolism Disorders Phytocomplex in the Correction of Carbohydrate Metabolism
}

\author{
Marat I. KALIMULLIN ${ }^{1 *}$, Sai-Suu S. SADI ${ }^{1}$, Alexander N. AVSTRIEVSKIKH ${ }^{1}$, \\ and Valery M. POZNYAKOVSKY ${ }^{1}$ \\ ${ }^{1}$ Kuzbass State Agricultural Academy, Kemerovo, Russian Federation \\ *Correspondence: sd@leszdrav.ru
}

\begin{abstract}
An herbal composition in the form of a biologically active additive (BAA) has been developed, the prescription of which is aimed at correcting metabolic processes in Diabetes Mellitus (DM) of the 2 type. The prescription formula of the specialized product is scientifically substantiated taking into account the biochemical characteristics and synergistic properties of raw ingredients and their active principles. The innovative technology for the production of dietary supplements is a tablet form of a bioactive complex that is received by pressing main and excipients components. Its advantage is the ability to accurately dispense, small volume of tablet form and ease of storage; a special film coating provides tablet strength and protection against aggressive external influences. There were established some regulated quality indicators, including nutritional values, which determine the functional properties of a specialized product. Thus 1 tablet contains not less than: manganese - $0.8 \mathrm{mg}$; zinc - $2.3 \mathrm{mg}$; chrome $0.1 \mathrm{mg}$; tannins - 20 $\mathrm{mg}$; flavonoids - $10 \mathrm{mg}$; vitamin C $-8.6 \mathrm{mg}$. The effectiveness and functional orientation of dietary supplements has been proven in clinical studies by including in the diet of patients with 2 type of diabetes - 1 tablet 2 times a day for 1 month, together with sugarlowering therapy. Patients, who were taking the phytocomplex, had decrease in blood glucose, total cholesterol and triglycerides against the background of an improvement in overall well-being and a decrease in body mass index.
\end{abstract}

Keywords: herbal complex, composition, quality, efficiency, diabetes of the 2 type.

\section{Introduction}

The development of healthy nutrition products is one of the priority areas for the development of modern nutrition. The main vector is aimed at sharing the accumulated experience of traditional and scientific medicine [1-3]. Great importance is given to the development of specialized food products - as the most affordable and effective way to correct nutrition and health [4-8]. One of the common diseases associated with impaired carbohydrate-fat metabolism is diabetes of the 2 type, which requires urgent preventive measures and comprehensive treatment measures, where the nutritional factor is given a priority [9-11]. 


\section{Materials and Methods}

As the objects of study there were used raw ingredients of the prescription composition of dietary supplements and the finished form of a specialized product. The effectiveness and functional orientation of the developed product have been confirmed in clinical trials in a group of patients with Diabetes Mellitus (DM) of the 2 type. Patients took dietary supplements in the amount of 1 tablet 2 times a day with meals on the background of sugar-lowering therapy with a pharmaceutical drug Maninil-5; the control group took only pharmacotherapy. The duration of the research was 1 month. To assess the functional properties and effectiveness of the developed product, clinical methods were used to study the dynamics of body weight, overweight, blood pressure (BP), basal and after-food glycemia, and biochemical blood parameters.

\section{Results}

The material on the development and study of the quality and effectiveness of natural herb compositions in the form of dietary supplements is presented. The qualitative and quantitative composition of the prescription formula of a specialized product is scientifically substantiated basing on the characteristics of the raw ingredients and their active principles. There were established regulated quality indicators, including nutritional values, determining the functional properties. Clinical trials of dietary supplements have been carried out as evidence of the effectiveness and functional orientation of the developed product.

The prescription composition of dietary supplements includes the following components, mg / 1 table (500 mg): blueberries (shoots) - 100; birch (leaf) - 37.5; premix 1-03 - 37.5, which includes: vitamins cyancobalamin - $0.4 \mathrm{mcg}$; retinol - 0.2; pantothenic acid - 0.89; tocopherol - 0.9; riboflavin - 0.19; cholecalciferol - $1.35 \mathrm{mcg}$; pyridoxine 0.23 , thiamine 0.19; folates - $67.5 \mathrm{mcg}$, niacin - 2.1; Vitamin H - 24.6 mcg; C - 10.3; lingonberry (leaf) 35; artichoke (root) - 25; knotgrass (grass) - 25; nettle (leaf) - 25; elecampane (root) - 25; highlander bird (grass) - 25; peppermint (leaf) - 12.5; burdock (root extract) - 12.5; raspberries (leaf extract) - 12.5; ginger (root) - 10; quercetin - 7.5; routine - 7.5; bromelain - 5; ginkgo biloba (extract) - 5; papain - 5; sublimated garlic - 5; zinc oxide - 3.3 (zinc 2.3); L-Carnitine - 2.5; coenzyme $Q_{10}$ - 2.5; manganese sulfate - 2.5 (manganese - 0.8); octacosanol - 1.25; chromium picolinate - 0.83. Excipients: MCC - 65.9; starch - 7.21; talc 6.51; hydroxypropyl methylcellulose - 0.01; maltodextrin - 0.001; titanium dioxide - 0.005 .

It was noted that the roots of artichoke, elecampane and ginger, birch leaves, blueberries and raspberries have an active influence on reducing the amount of sugar in the blood. Correction of carbohydrate and fat metabolism is carried out under the influence of Lcarnitine, B vitamins, manganese and chromium with the synergistic combined participation of burdock extract. The effect of strengthening the vascular walls is observed in the implementation of the physiological functions of the extract of ginkgo biloba, nicotinamide, tocopherol and ascorbic acid with the participation of quercetin. At the same time, a decrease in blood viscosity and an improvement in microcirculation are observed. The anti-inflammatory and antimicrobial properties of the product are realized by the pharmacological characteristics of wormwood in the presence of bromelain and papain enzymes. Garlic and knotgrass exhibit immunomodulating effects, thereby ensuring the prevention of immunodeficiency conditions. Knotgrass exhibits functions of regeneration of nerve tissue, normalization of digestion in the presence of a calming and 
choleretic effect. Lingonberry leaf normalizes the functioning of the kidneys, carries out a diuretic and antiseptic effect. The characteristics of the active ingredients of the phytocomplex described above are distinguished by a combination of a sugar-lowering effect while supporting the functional activity of the pancreas [12-17].

In the production of dietary supplements, innovative tabletting technology was used. The advantage of tablet technology is dosing of biologically active ingredients according to the recipe; small volume of tablet form and ease of storage. Due to the film coating, strength and its protection against the aggressive influence of xenobiotics is ensured. The developed technology can be positioned as innovative and in demand in the production of the food group in question. Based on the results of the tests (microbiological, organoleptic, physicochemical), regulated quality characteristics were established (Table 1).

Table 1. Regulated quality indicators of dietary supplements

\begin{tabular}{|c|c|}
\hline Indicator & Value \\
\hline Appearance & Oval form of tablets, with or without coated membrane \\
\hline Tablet mass, average, mg & $0.47-0.53$ \\
\hline Coated membrane & White \\
\hline Disintegration, min, no more than & 30 \\
\hline Color of the tablet & Green (with shades and splashes) \\
\hline Smell and taste & Specific \\
\hline Breaking strength, $N$, not less than & 90 \\
\hline Abrasion resistance, $\%$ not less than & 97 \\
\hline \multicolumn{2}{|l|}{ Nutritional value } \\
\hline Index & Content in 1 tab., Mg, not less \\
\hline Ascorbic acid & 8.6 \\
\hline Chrome & 0.1 \\
\hline Zinc & 2,3 \\
\hline Flavonoids & 10 \\
\hline Tannins & 20 \\
\hline Manganese & 0.8 \\
\hline
\end{tabular}

The nutritional value of the phytocomplex determines its properties as a functional product used to correct the amount of glucose in blood, normalize the function of the pancreas and support metabolism in diabetes mellitus.

Patients taking the phytocomplex in addition to the diet were studied according to the level of glucose in the blood after a meal and on an empty stomach. A more complete 
assimilation of glucose was noted on the basis of a decrease in its amount in the blood (Figire 1).

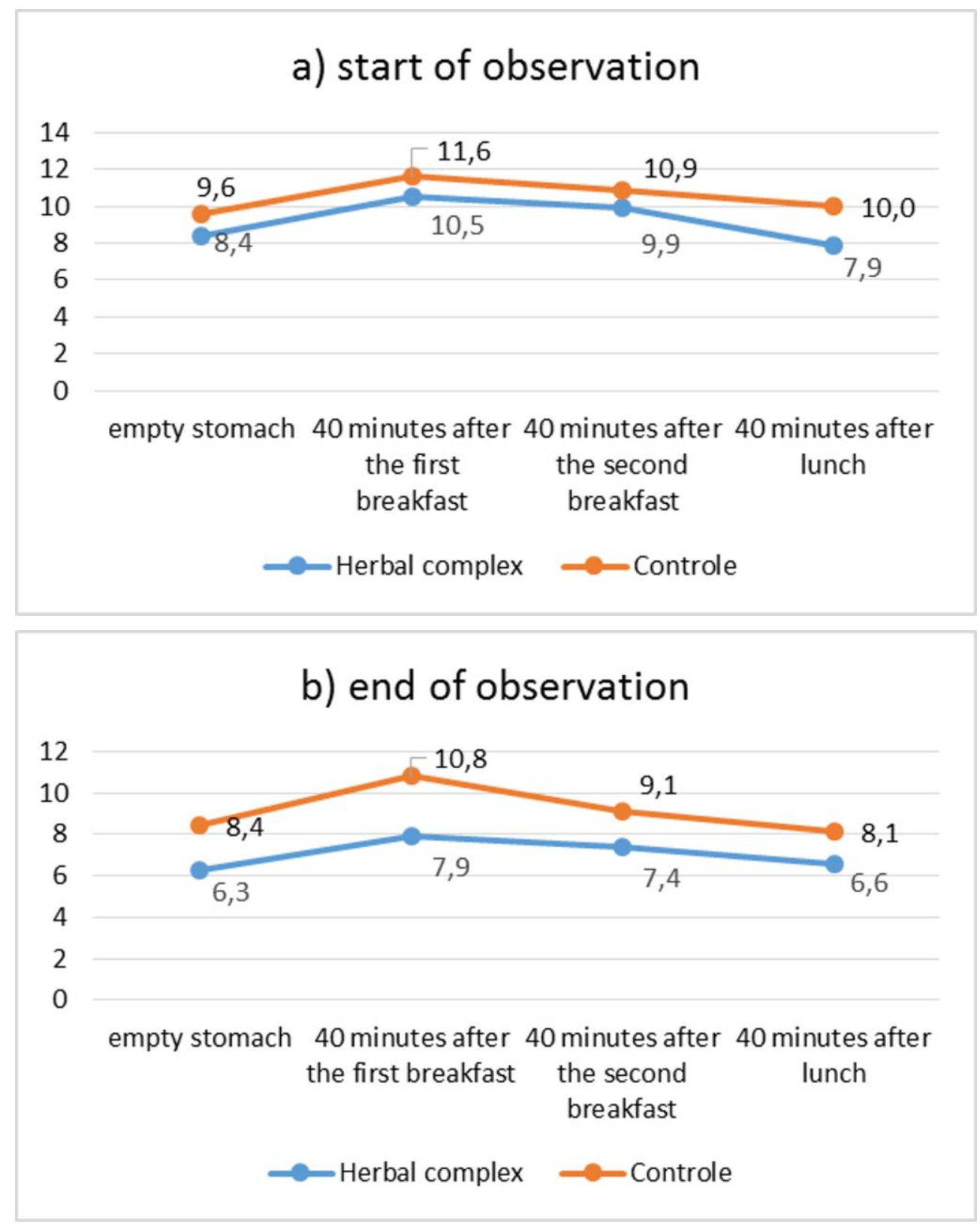

Figure 1. The concentration of glucose in the blood before and after meals, $\mu \mathrm{mol} / \mathrm{L}$

The content of triglycerides and cholesterol decreased by $23 \%$ and $28 \%$, respectively, from the initial level, which indicates positive changes in lipid metabolism. As a positive result, it should be noted that patients lack dry mouth and thirst, and improve overall well-being. After 1 month, the body mass index decreased. All this indicates the presence of evidence on the preventive effect of the phytocomplex in relation to the negative dynamics of diabetes. 
An expert opinion was obtained from the Federal Service for Surveillance on Consumer Rights Protection and Human Wellbeing of the Russian Federation and the test center of the Institute of Nutrition of the Russian Academy of Sciences on the positive impact of the developed product on glucose metabolism, the function of the digestive system and pancreas with activation of microcirculation and normalization of carbohydrate-fat metabolism.

\section{Conclusion}

Recommendations have been developed on the intake of the phytocomplex in the presence of the 2 type of diabetes and glucose tolerance, followed by a program to prevent possible complications and improve the quality of life. Adults take one tablet 2 times a day with meals, duration - 1 month.

Established regulated storage periods of sales - 3 years with the necessary margin of "strength" - 3 months.

A specialized product is included in the Federal Register, the use of GMP 9001, 22000 standards in the production guarantees the stability of quality characteristics and competitiveness.

\section{References}

(1) Austrievskikh, A. N.; Vekovtsev, A. A.; Poznyakovsky, V. M. Health food products: new technologies, quality assurance, application efficiency (in Russian); Siberian University Publishing House: Novosibirisk, 2005.

(2) Pokrovskiy, V. I.; Romanenko, G. A.; Knyazhev, V. A.; Gerasimenko, N. F.; G.G., O.; Tutelian, V. A.; Poznyakovskiy, V. M. Healthy Food Policy. Federal and Regional Levels; Sib. Univ. Publishing House: Novosibirsk, 2002.

(3) Food Ingredients in the Creation of Modern Food Products (in Russian); Tutelian, V. A., Nechaev, A. P., Eds.; DeLi Plus: Moscow, 2014.

(4) Poznyakovskiy, V. M. Nutrition Evolution and Nutriom Formation of the Modern Human (in Russian). Food Industry 2017, 2 (3), 5-12. https://doi.org/10.29141/2500-1922-2017-2-3-1.

(5) Poznyakovskiy, V. M.; Chugunova, O. V.; Tamova, My. Food Ingredients and Dietary Supplements (in Russian); INFRA-M: Moscow, 2017.

(6) Chereshnev, V. A.; Poznyakovskiy, V. M. The Problem of Food Security: National and International Aspects (in Russian). Food Industry 2016, 1 (1), 6-14.

(7) Lobach, E. Yu.; Poznyakovskiy, V. M. Methodogical Aspects and Operational Experience of the New Baa with Fargeted Functional Properties. Food and Raw Materials 2016, 4 (2), 66-74. https://doi.org/10.21179/2308-4057-2016-2-66-74.

(8) Popov, V. G.; Kadochnikova, G. D.; Poznyakovsky, V. M.; Khabarov, S. N. Improvement of the Methods of Extraction of Plant Raw Materials (in Russian). Ynternational Journal of Applied Engineering Research 2017, 12 (15), 5421-5429. 
(9) Gerasimenko, N.; Poznyakovsky, V.; Chelnakova, N. Methodological Aspects of High-Grade Safe Nutrition: Value in Maintaining Health and Working Capacity (in Russian). Human. Sport. Medicine 2017, 17 (1), 79-86. https://doi.org/10.14529/hsm170108.

(10) World Health Organization. Report on the Situation of Non-Communicable Diseases in the World; Geneva, 2010.

(11) Health of Russia: Atlas, 8th ed.; Bokeria, L. A., Ed.; A.N. Bakulev National Medical Research Center of Cardiovascular Surgery: M, 2012.

(12) Galgani, J. E.; Cortés, V.; Carrasco, F. Carbohydrate, Fat and Protein Metabolism in Obesity. In Metabolic Syndrome; Ahima, R. S., Ed.; Springer International Publishing: Cham, 2015; pp 1-22. https://doi.org/10.1007/978-3-319-12125-3_21-1.

(13) Mizgier, M. L.; Casas, M.; Contreras-Ferrat, A.; Llanos, P.; Galgani, J. E. Potential Role of Skeletal Muscle Glucose Metabolism on the Regulation of Insulin Secretion: Organ Crosstalk and Insulin Secretion. Obesity Reviews 2014, 15 (7), 587-597. https://doi.org/10.1111/obr.12166.

(14) Castro, C.; Corraze, G.; Firmino-Diógenes, A.; Larroquet, L.; Panserat, S.; Oliva-Teles, A. Regulation of Glucose and Lipid Metabolism by Dietary Carbohydrate Levels and Lipid Sources in Gilthead Sea Bream Juveniles. British Journal of Nutrition 2016, 116 (1), 19-34. https://doi.org/10.1017/S000711451600163X.

(15) Ludwig, D. S.; Friedman, M. I. Increasing Adiposity: Consequence or Cause of Overeating? JAMA 2014, 311 (21), 2167. https://doi.org/10.1001/jama.2014.4133.

(16) Hall, K. D.; Bemis, T.; Brychta, R.; Chen, K. Y.; Courville, A.; Crayner, E. J.; Goodwin, S.; Guo, J.; Howard, L.; Knuth, N. D.; et al. Calorie for Calorie, Dietary Fat Restriction Results in More Body Fat Loss than Carbohydrate Restriction in People with Obesity. Cell Metabolism 2015, 22 (3), 427-436. https://doi.org/10.1016/j.cmet.2015.07.021.

(17) Ble-Castillo, J. L.; Aparicio-Trapala, M. A.; Juárez-Rojop, I. E.; Torres-Lopez, J. E.; Mendez, J. D.; Aguilar-Mariscal, H.; Olvera-Hernández, V.; Palma-Cordova, L. C.; Diaz-Zagoya, J. C. Differential Effects of High-Carbohydrate and High-Fat Diet Composition on Metabolic Control and Insulin Resistance in Normal Rats. International Journal of Environmental Research and Public Health 2012, 9 (5), 1663-1676. https://doi.org/10.3390/ijerph9051663.

\section{Information about Authors}

Marat Ildusovich KALIMULLiN: Ph.D. in Economics, Doctoral Student of the basic Department of Food Industry and Functional Nutrition, Kuzbass State Agricultural Academy; 12 Karl Marx Str., Kemerovo, 650021, Russia; e-mail: sd@leszdrav.ru.

Sai-Suu Saiynoolovna SADi: Postgraduate Student of the basic Department of Food Industry and Functional Nutrition, Kuzbass State Agricultural Academy; 12 Karl Marx Str., Kemerovo, 650021, Russia; e-mail: saysuu.sadi@mail.ru. 
Alexander Nikolaevich AVSTRIEVSKIKH: D.Sc. in Engineering, Professor, Department of Food Industry and Functional Nutrition, Kuzbass State Agricultural Academy; General Director of the Research and Production Association "Art Life"; 8/2 Nakhimov Str., Tomsk, 634034, Russia; e-mail: alexcander@artlife.ru.

Valery Mikhailovich POZNYAKOVSKY: D.Sc. in Biology, Honored Scientist of the Russian Federation, Professor, Head of the Scientific and Educational Center "Processing of Agricultural Raw Materials and Food Technology", Head of basic department "Food Industry and Functional Nutrition", Kuzbass State Agricultural Academy; 12 Karl Marx Str., Kemerovo, 650021, Russia; e-mail: pvm1947@bk.ru. 